\title{
Preconcentration and Determination of Pantoprazole by Solid-phase Extraction Coupled with Spectrophoto- metry Using Iron Oxide Nanoparticles Modified with Cetyltrimethylammonium Bromide
}

\author{
Maryam Sayyahmanesh $^{1}$, Ebrahim Naghian ${ }^{2}$, Hamed Sahebi $^{2}$, Sara Asgari ${ }^{2}$ \\ ${ }^{1}$ Department of Chemical and Petroleum Engineering, Sharif University of Technology, Tehran, Iran \\ ${ }^{2}$ Department of Chemistry, Islamic Azad University, Karaj branch, Iran \\ \Corresponding author: E-mail: sayyahmanesh@che.sharif.ir
}

Received: Aug. 21, 2015; Accepted: Sept. 17, 2015; Published: Sept. 30, 2015.

Citation: Maryam Sayyahmanesh, Ebrahim Naghian, Hamed Sahebi and Sara Asgari. Preconcentration and Determination of Pantoprazole by Solidphase Extraction Coupled with Spectrophotometry Using Iron Oxide Nanoparticles Modified with Cetyltrimethylammonium Bromide. Nano Biomed. Eng. 2015, 7(3), 102-110.

DOI: 10.5101/nbe.v7i3.p102-110.

\begin{abstract}
Solid phase extraction coupled with spectrophotometric detection was applied to trace amounts of Pantoprazole (PP) drug using Cetyltrimethylammonium bromide coated-iron oxide magnetite nanoparticles CTAB@ $\mathrm{Fe}_{3} \mathrm{O}_{4}$ MNPs. After characterization of the prepared nano-adsorbents, experimental parameters affecting the extraction efficiency of the developed method were optimized. The results obtained showed that this proposed approach is applicable in concentrations ranging from 0.1 to $1.5 \mu \mathrm{g} / \mathrm{ml}\left(\mathrm{R}^{2}=0.9958\right)$ indicating that follows Beer's-Lambert law. The limit of detection and the limit of quantification calculated to be 0.014 and $0.04 \mu \mathrm{g} / \mathrm{ml}$, respectively. The repeatability of the proposed method was evaluated with studying intra-day and inter-day precisions described by relative standard deviations. Eventually, two samples of natural waters as well as samples of human plasma were analyzed using the proposed method. Satisfactory precision and recoveries in the complex matrices were achieved.
\end{abstract}

Keywords: Solid phase extraction; nanoparticles modified with Cetyltrimethylammonium bromide; spectrophotometry

\section{Introduction}

The inter surface of stomach is formed of numerous gastric pits which release gastric acid secretions. High contents of these secretion lead to flow back up to the food pipe and cause Laryngopharyngeal reflux (LPR) problems. Pantoprazole (PP) with commercial name of Protonix is classified in Proton pomp inhibitor drugs category which reduces the amount of acid in stomach.
PP suppresses proton pomp activation owing to covalent attachment to hydrogen-potassium adenosine triphosphates enzymes (on the surface of gastric parietal cells), harnessing secretion of hydrogen ions [1-3].

Determining and measuring the drug in water, wastewater treatment and biological fluids to reduce toxicity is of significant importance. That is why several analytical methods were investigated to assay 
PP drug in environmental and biological samples using high-performance liquid chromatography (HPLC) [4-7], reversed-phase high-performance liquid chromatography (RP-HPLC) [8-10], high performance thin layer chromatography (HPTLC) [11, 12], voltammetry analysis [13-15], liquid chromatographytandem mass spectrometry (LC-MS) $[16,17]$ and UVspectrophotometry [18, 19]. However, in recent years, the usage of nanostructured materials has drawn great attention of researchers as adsorbents to separation, extraction and illumination of various organic and inorganic species from complex matrices [20]. Liquidliquid extraction technique, a method which the target transmission accomplishes on the basis of equilibrium process, faced with some restrictions. Need for high purity toxic eluant, limited usage to non-polar targets, high cost of organic solvent and mandatory restrictions of protection agenesis exerted to use safe and benign materials with environment are some of shortcomings accompanying with it [21]. Sample pretreatment to avoid interferences, extra-dilution and wash off harmful contamination are difficulties attributed to solid-phase extraction (SPE) packedcolumns which are time-consuming, costly and need skilled operators to automate [22, 23]. Hence, emerge of solid phase extraction on the basis of nano/microstructure materials solved these problems. Among different nanoscale materials, magnetite nanoparticles (MNPs) are widely being used because of considerable properties such as low toxicity, biocompatibility, low mass transfer resistance and strong magnetism which causes to be easily isolated from the reaction system with an external magnetic field [24, 25]. Besides, high ratio of surface area to volume of MNPs eventuates in excellent loading capacity and extraction efficiency [26]. As a result of which, they may supersede conventional methods of solid-phase extraction cartridges and liquid-liquid techniques for rapid and facile determination of various spacious. Nevertheless, they tend to be accumulated to large clusters and oxidized spontaneously in the presence of oxygen during storage process which has adverse effect on their applications. To overcome these limitations, they are functionalized with appropriate materials to enhance their stability, better dispersion in aqueous media and finally form homogenous suspensions. More importantly, in this way they are also predisposed to further attachments with target molecules [27, 28].

To effective application of solid phase extraction process, iron oxide MNPs are coated with a shell of ionic surfactants, functionalized-mineral coatings by surfactants or other materials. Mineral oxides adsorbents are coated with surfactant molecules electrostatically (coulombic attractions) and form hydrophobic monolayer hemimicelles and ionic bilayer admicelles. This dual mechanism of surfactants, hydrophobic and electrostatic interactions, has led to be used to extraction and determination of various analyte molecules. Several studies applied surfactants such as sodium dodecyl sulfate (SDS) and Cetyltrimethylammonium bromide (CTAB) to modify the surface of either MNPs [29-35] or functionalized silica, alumina and carbon coated MNPs [36-38]. They have taken advantage of these structures to solid phase extraction of bioactive constituent in pharmaceutics and environmental contaminants.

In the present study, we employed the structure of Cetyltrimethylammonium bromide coated with iron oxide magnetite nanoparticles ( $\left.\mathrm{CTAB} @ \mathrm{Fe}_{3} \mathrm{O}_{4} \mathrm{MNPs}\right)$ for preconcentration and determination of $\mathrm{PP}$ drug by UV-visible spectroscopy detection. All experimental parameters were investigated to specify the condition under which the best extraction efficiency could be obtained. After optimizing parameters such as the $\mathrm{pH}$ of the solution, the amount of CTAB, extraction time, the amount of adsorbent $\left(\mathrm{Fe}_{3} \mathrm{O}_{4}\right)$, the type and amount of detergent (solvent), desorption time, the proposed nanocomposites were exploited in aqueous and human plasma samples. Finally, the obtained results are compared with previously reported studies conducted on determination of PP. To our knowledge, this is a first research have been conducted on SPE of PP drug using MNPs as adsorbent.

\section{Experimental}

\section{Apparatus and Chemicals}

Spectral measurements were performed by UVVIS spectroscopy (Lambda-25 model, Perkin-Elmer). Scanning electron microscopy (EM3200 model, KYKY), X-ray diffraction analysis (X'pert-MPD model, Philips), vibrating sample magnetometer (Meghnatis Daghigh Kavir Co. Iran), pH-meter (UB-10 model, Denver instrument) were used in this study.

Pantoprazole Sodium Sesquihydrate (99.96\%), $\mathrm{Fe}_{3} \mathrm{O}_{4}$ nanoparticles $(99.5 \%$, particle size $15-20 \mathrm{~nm}$ ) and two-distilled water were purchased from Hakim, US research nanomaterials Inc., and zolal sabalan Co. (Iran), respectively. CTAB (analytical grade), Sodium 
hydroxide, hydrochloride acid (analytical grade), and acetonitrile (HPLC-grade), all were received from Merck (Germany). Ethanol (analytical grade) and Methanol (HPLC-grade) were also received from Romil (England).

\section{SPE procedure}

The SPE procedure was generally accomplished as follows: $100 \mathrm{ml}$ of preliminary sample solution (100 $\mu \mathrm{g} / \mathrm{ml}$ ) was prepared by adding $0.01 \mathrm{~g}$ of PP volumed by two-distilled water and samples of $50 \mathrm{ml}$ are taken from the stock solution. Then, $0.1 \mathrm{~g}$ of adsorbents and $5 \mathrm{ml}$ of CTAB solution $(0.2 \%, \mathrm{w} / \mathrm{v})$ were added to each sample and ultrasonicated for $10 \mathrm{~min}$. MNPs are separated using a magnet and the supernatant collected was decanted off. CTAB $@ \mathrm{Fe}_{3} \mathrm{O}_{4}$ MNPs were dispersed in $5 \mathrm{ml}$ of methanol as solvent and ultrasonicated for 10 min once again. Absorbance of samples was recorded spectrophotometrically at $290 \mathrm{~nm}$. This wavelength for maximum absorbance of PP drug was measured previously, results not shown. The entire steps of the process are shown in Fig. 1.

\section{Natural waters and human plasma sampling}

Subterranean water sample and city water were collected from water well and water tape of lab (Shahrak Gharb, Tehran), respectively. $100 \mathrm{ml}$ of preliminary stock solution with $0,0.5$ and $1 \mu \mathrm{g} /$ $\mathrm{ml}$ concentrations was added to each sample. $3 \mathrm{ml}$ plasma obtained from volunteers have not taken PP drug and sampled in Laleh Hospital's laboratory, Tehran, Iran. Then, it was centrifuged immediately at $4000 \mathrm{rpm}$ for $20 \mathrm{~min}$ and stored in freezer at $-20^{\circ} \mathrm{C}$. Before processing time, plasma solution was allowed to be thawed at room temperature. To evaluate the repeatability of the experiment, each sample was triplicated as described above but under optimized conditions which will be discussed.

\section{Results}

\section{Characterization of the prepared CTAB@ $\mathrm{Fe}_{3} \mathrm{O}_{4}$ MNPs}

Surface morphology of the $\mathrm{Fe}_{3} \mathrm{O}_{4}$ and CTAB@ $\mathrm{Fe}_{3} \mathrm{O}_{4}$ MNPs are illustrated in Fig. 2(a), (b). Electron microscopy images which taken in same magnitude $(40 \mathrm{~K})$ show that the morphology of these particles is quasi-spherical and particle size of $\mathrm{Fe}_{3} \mathrm{O}_{4}$ MNPs is almost similar to the nanoparticles coated by CTAB. Fig. 2(c), (d) presents XRD profiles of $\mathrm{Fe}_{3} \mathrm{O}_{4}$ and CTAB $@ \mathrm{Fe}_{3} \mathrm{O}_{4}$ MNPs which operating at $\lambda=178897 \AA$ and $2 \theta$ between 5 and 118 degree. The presence of six diffraction peaks in both diagram confirm the spinal structure of these particles. As can be seen, there is no obvious difference between MNPs before and after being coated with $\mathrm{CTAB}$ indicating coated $\mathrm{CTAB}$

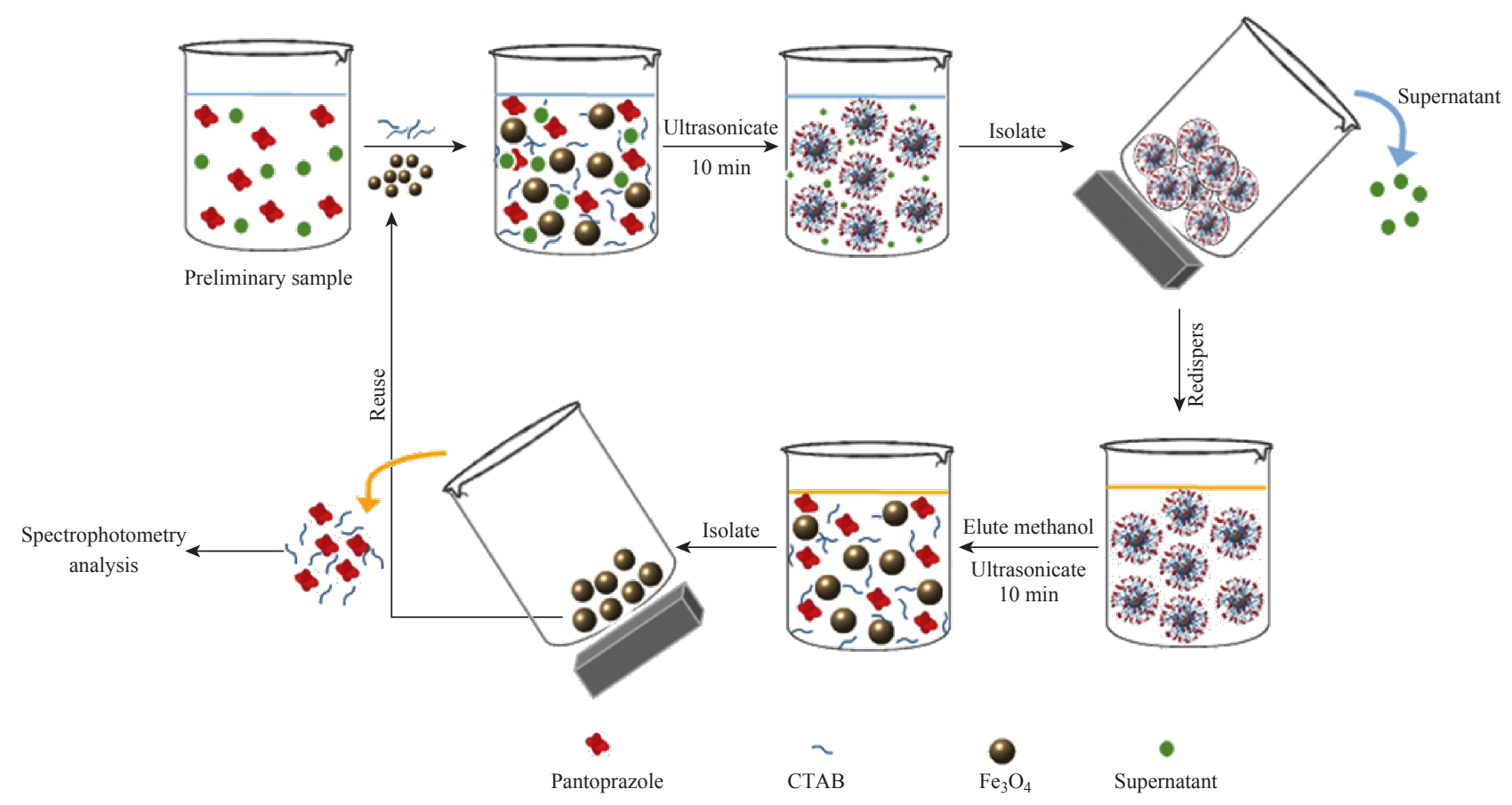

Fig. 1 Schematic illustration of the CTAB@ $\mathrm{Fe}_{3} \mathrm{O}_{4} \mathrm{MNPs}$ preparation and their application as SPE adsorbent. 

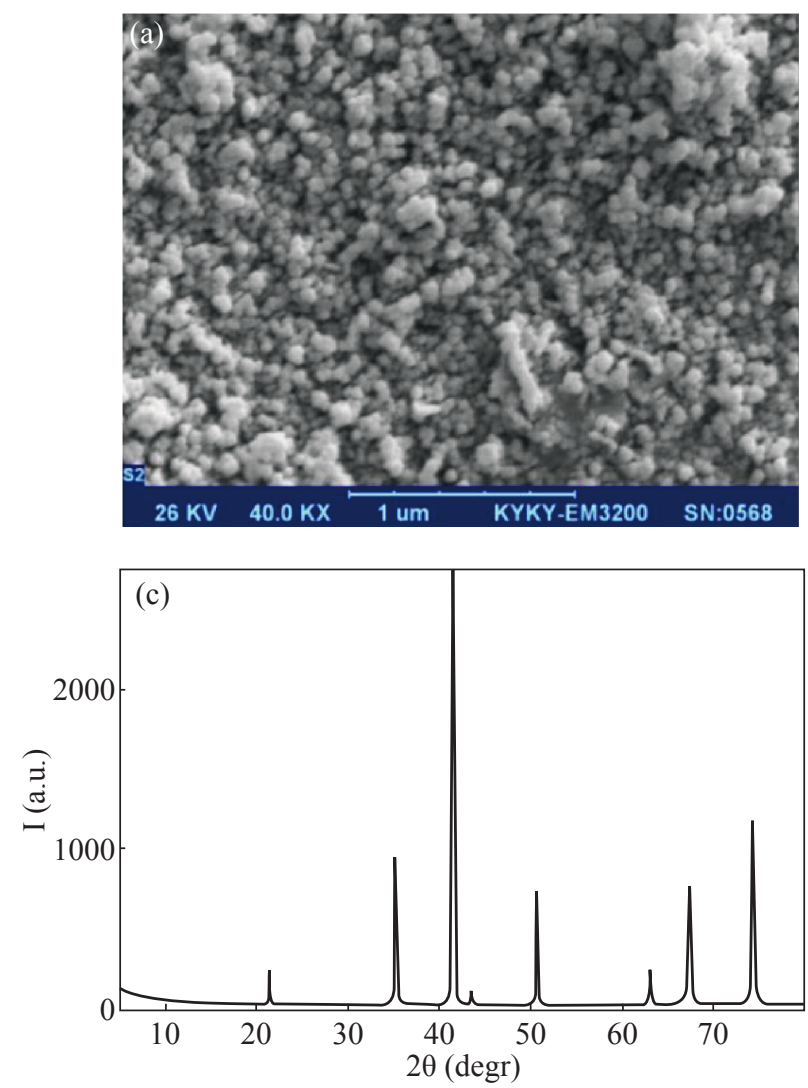
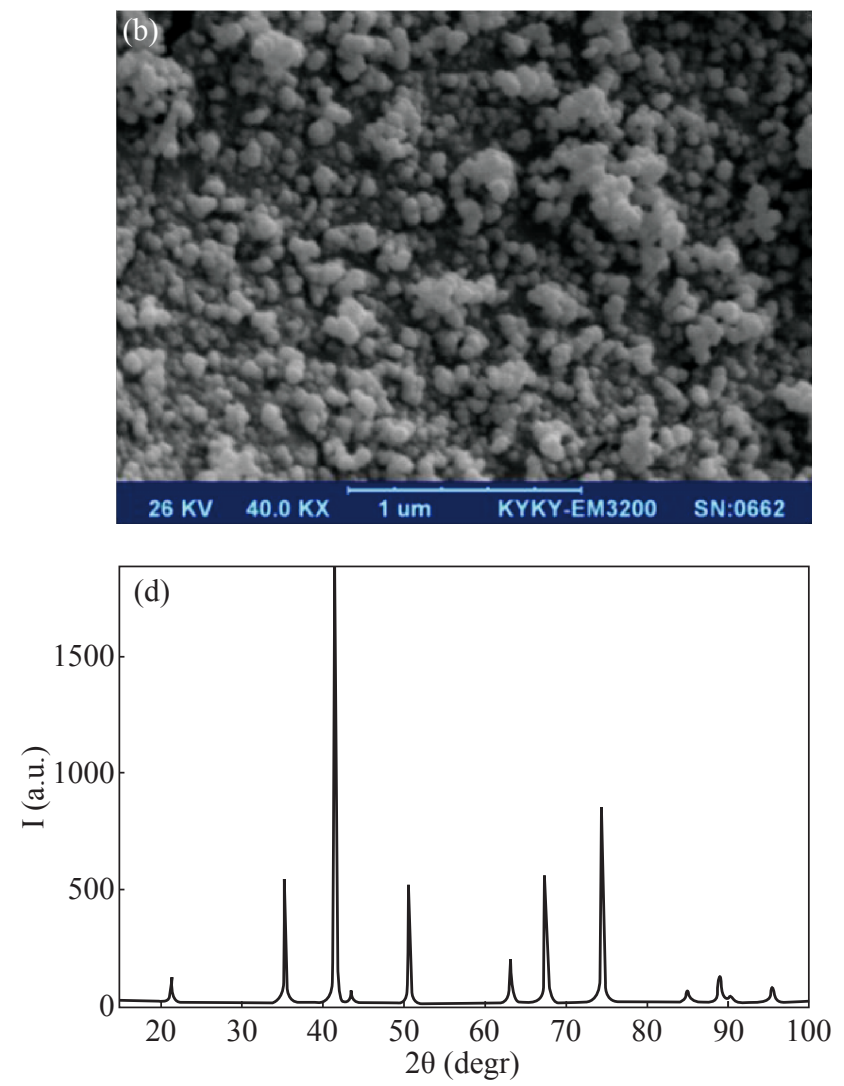

Fig. 2 SEM image of (a) $\mathrm{Fe}_{3} \mathrm{O}_{4}$ MNPs and (b) CTAB@ $@ \mathrm{Fe}_{3} \mathrm{O}_{4}$ MNPs; and x-ray diffractogram of (c) $\mathrm{Fe}_{3} \mathrm{O}_{4}$ MNPs and (d) CTAB@ $\mathrm{Fe}_{3} \mathrm{O}_{4} \mathrm{MNPs}$.

on MNPs is just an amorphous layer. The mentioned characterizations demonstrate that the modification process of $\mathrm{Fe}_{3} \mathrm{O}_{4} \mathrm{MNPs}$ surface was physically (surface adsorption).

To examine magnetite properties of both MNPs and modified MNPs, VSM analysis was carried out. The magnetization curve, shown in Fig. 3, revealed being superparamagnetic of these particles implying no

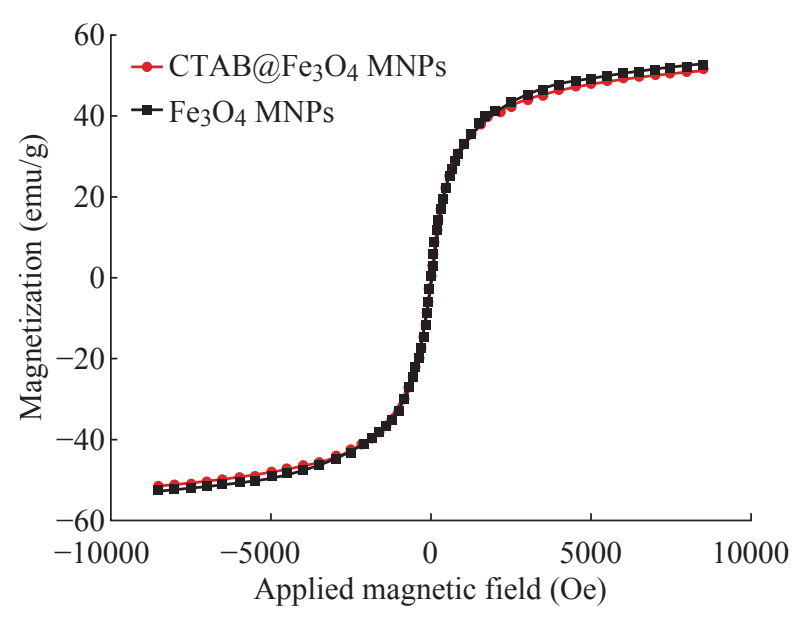

Fig. 3 Magnetization curves of $\mathrm{Fe}_{3} \mathrm{O}_{4} \mathrm{MNPs}$ and $\mathrm{CTAB} @ \mathrm{Fe}_{3} \mathrm{O}_{4}$ MNPs. magnetism property after the removal of the external magnetite field. Hence, they are being manipulated to be simply separated from the bulk of solution. For $\mathrm{CTAB} @ \mathrm{Fe}_{3} \mathrm{O}_{4}$ MNPs, saturated magnetization is of $55(\mathrm{emu} / \mathrm{g})$ value, while just a very slightly decline observed compare to that of $\mathrm{Fe}_{3} \mathrm{O}_{4}$ MNPs. All the characterization analyses conducted showed that coating process has not been significantly changed the structure of $\mathrm{Fe}_{3} \mathrm{O}_{4}$ MNPs.

\section{Effect of $\mathrm{pH}$}

As isoelectric point plays a main role to control over charge density of mineral oxides, selecting the preferable $\mathrm{pH}$ is considered important to obtain the most surfactants loading on MNPs, ultimately, eventuating in better extraction efficiency. This point for $\mathrm{Fe}_{3} \mathrm{O}_{4} \mathrm{MNPs}$ has been reported previously equal to $\mathrm{pH} 6.5$ and thus efficient interaction was to be expected in pHs more than 6.5 [29]. By adding CTAB as a cationic surfactants to the mixture in a basic condition of reaction, MNPs surfaces become anodic which underlie to attract these cationic surfactants electrostatically. As soon as a monolayer accumulation of micelles surrounded $\mathrm{Fe}_{3} \mathrm{O}_{4}$ MNPs (Hemimicelles), 


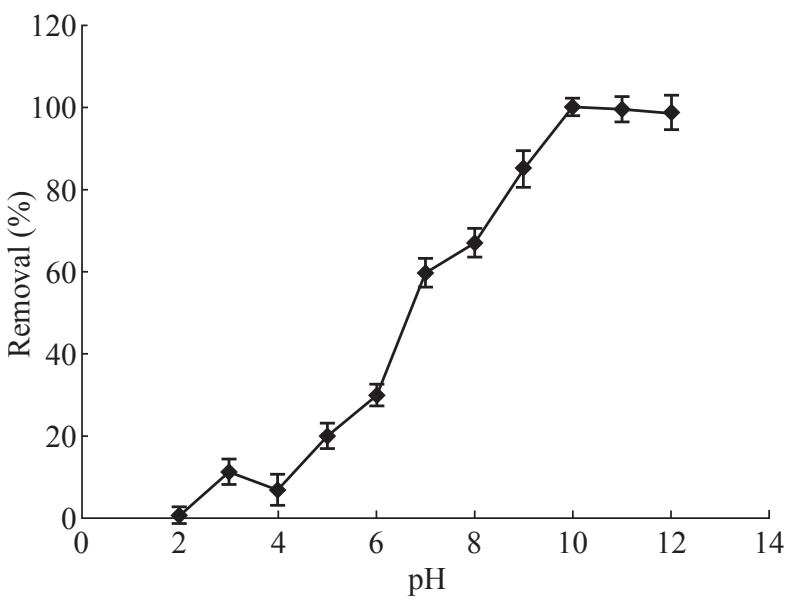

Fig. 4 Effects of $\mathrm{pH}$ on drug absorbance level: $\mathrm{PP}$ concentration $1 \mathrm{mg} \cdot \mathrm{ml}^{-1}$, solution volume $50 \mathrm{ml}, 5 \mathrm{~mL}$ of CTAB $(0 / 2 \% \mathrm{w} / \mathrm{v})$, $0.1 \mathrm{~g}$ of absorbent, contact time $10 \mathrm{~min}, 5 \mathrm{ml}$ of methanol as desorbent (solvent), desorption time $10 \mathrm{~min}$.

the remained micelles formed the second layer. Due to the hydrophobic interchain interactions, di-layer surfactants of admicelles are formed. For $\mathrm{pH}$ values lower than isoelectric point of $\mathrm{Fe}_{3} \mathrm{O}_{4} \mathrm{MNPs}$, the negative charge density of the MNPs surface decreases which result in significant drop in analytical signal. Hence, the effect of $\mathrm{pH}$ was investigated between 2 to 12 and the results acquired were showed in Fig. 4. It is clear that the maximum extraction efficiency is attained once $\mathrm{pH}$ is fixed at 10 .

\section{Optimization of the CTAB amount}

The effect of the CTAB amount was studied by adding various amounts of CTAB between 1 to $7 \mathrm{ml}$ to the reaction mixture. Results, brought in Fig. 5, demonstrate that with adding $5 \mathrm{ml}$ of CTAB a dramatic increase in extraction efficiency was acquired while for greater extent of CTAB a sharp drop was observed. This phenomenon is justifiable because when the amount of CTAB exceeds critical micelle concentration (CMC) level result in the growth of micelles in the solution of reaction freely. Therefore, the aliquot of analyte could be lost through these micelles and not be extracted magnetically.

\section{Contact time assay}

PP drug adsorption process on MNPs was allowed to proceed in different times of reaction. The optimal time at which the reaction accomplished was obtained $7 \mathrm{~min}$, results not shown. High surface area, homogeneous distribution of the particles and excellent affinity between these nano-absorbent and drug analyte

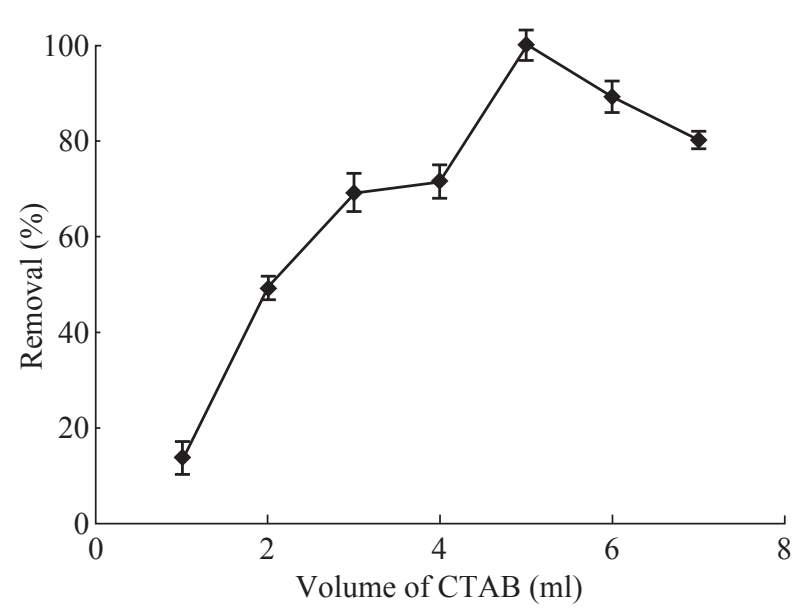

Fig. 5 Effects of CTAB amount $(0.2 \% \mathrm{w} / \mathrm{v})$ on drug absorbance level: PP concentration $1 \mathrm{mg} \cdot \mathrm{ml}^{-1}$, solution volume $50 \mathrm{ml}, \mathrm{pH}$ $10,0.1 \mathrm{~g}$ of absorbent, contact time $10 \mathrm{~min}, 5 \mathrm{ml}$ of methanol as desorbent (solvent), desorption time $10 \mathrm{~min}$.

lead to reach such a fast extraction process. This is a superiority of the MNPs over conventional SPE and other Micro-oriented techniques which necessitates 30 to $60 \mathrm{~min}$ period of time to reach equilibrium state.

\section{Optimization of the amount of $\mathrm{Fe}_{3} \mathrm{O}_{4}$ MNPs}

Due to the high ratio of surface area to the volume of the nano particles, they are a promising alternative for conventional micro-adsorbent. Hence, only a small amount of MNPs is required to achieve significant results. The effect of the adsorbent amount on extraction efficiency was studied. To that aim, various quantities of $\mathrm{Fe}_{3} \mathrm{O}_{4}$ MNPs ranging from 0.05 to $0.15 \mathrm{~g}$ was dispersed into the reaction mixture and subjected to evaluate. It was found that, from Fig. 6, the optimal amount of $\mathrm{Fe}_{3} \mathrm{O}_{4}$ MNPs for $5 \mathrm{ml}$ of CTAB is $0.07 \mathrm{~g}$.

\section{Optimization of desorption conditions}

Adsorption process of drug from the MNPs surface takes place by a solvent. Organic solvents can simply deteriorate the structure of formed hemimicelles. Adsorption process of the PP was spectrophotometrically tested by ethanol, methanol and acetonitrile. Due to the better PP removal by ethanol, it was considered as desorbing solvent. Then, the optimal amount of the requisite solvent is determined at different volume of ethanol between 1 to $8 \mathrm{ml}$. Fig. 7 presented that just $1 \mathrm{ml}$ of ethanol is quite enough to separate PP quantitatively from their carrier surface. To reach the effective desorption duration, time-dependent changes in the adsorbed drug level were also perused 


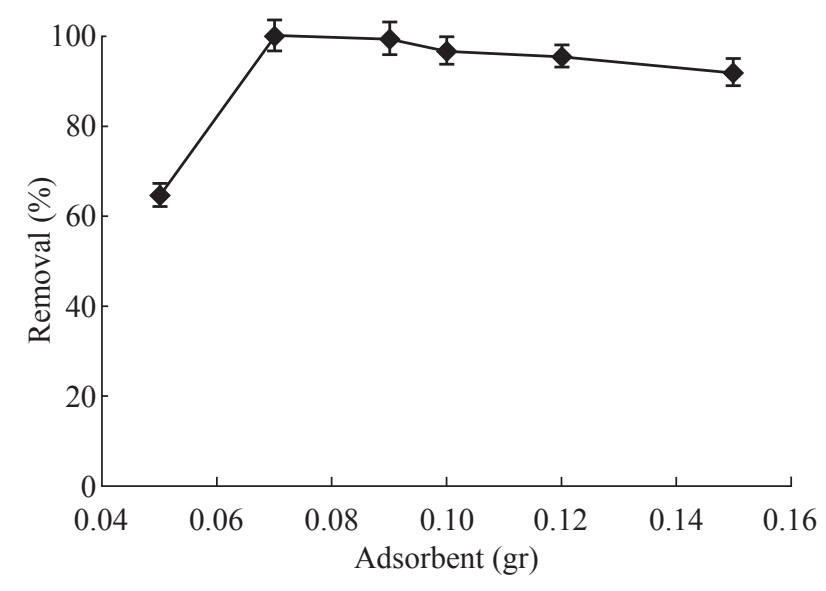

Fig. 6 Effects of adsorbent amount on drug absorbace level: PP concentration $1 \mathrm{mg} \cdot \mathrm{ml}^{-1}$, solution volume $50 \mathrm{ml}, \mathrm{pH} 10,5 \mathrm{~mL}$ of CTAB $(0 / 2 \% \mathrm{w} / \mathrm{v})$, contact time $7 \mathrm{~min}, 5 \mathrm{ml}$ of methanol as desorbent (solvent), desorption time $10 \mathrm{~min}$.

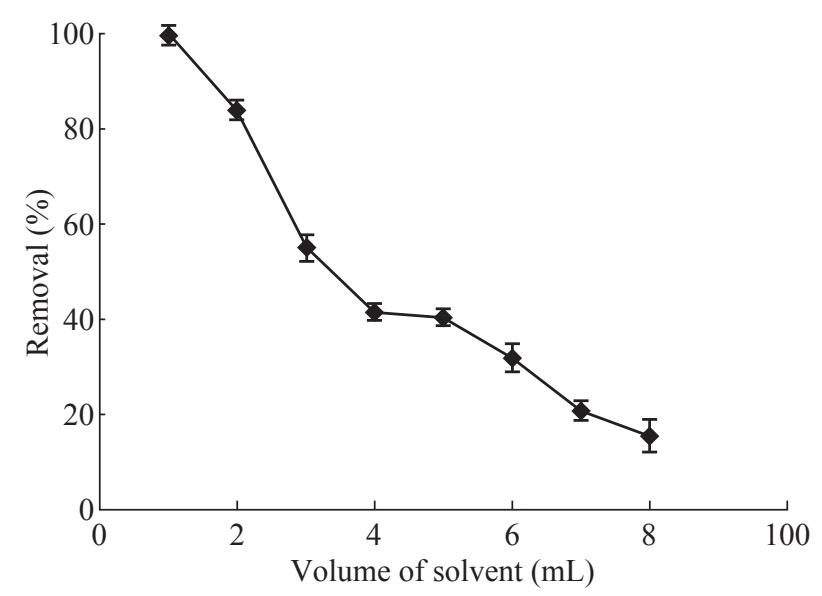

Fig. 7 Effects of desorbent (solvent) volume on drug absorbance level: PP concentration $1 \mathrm{mg} \cdot \mathrm{ml}^{-1}$, solution volume $50 \mathrm{ml}, \mathrm{pH}$ $10,5 \mathrm{~mL}$ of CTAB $(0 / 2 \% \mathrm{w} / \mathrm{v}), 0.07 \mathrm{~g}$ of absorbent, contact time $7 \mathrm{~min}$, desorption time $10 \mathrm{~min}$.

and showed in Fig. 8. Accordance with this figure, standing for 2 min will provide sufficient contact time for analyte target and solvent to achieve complete desorption of PP drug.

\section{Effect of the volume of sample solution}

The impact of the sample volume on preconcentration of samples was examined while the amount of analyte target, MNPs, and CTAB were kept constant. By doing so, the maximum diluted sample in which highest preconcentration factor and extraction efficiency could be attained. As it can be seen from Fig. 9 just insignificant change is observable in extraction efficiency till the $100 \mathrm{ml}$ of sample. Increase of sample volume above $100 \mathrm{ml}$ causes to decrease in extraction efficiency due to the overconcentrated of target analyte

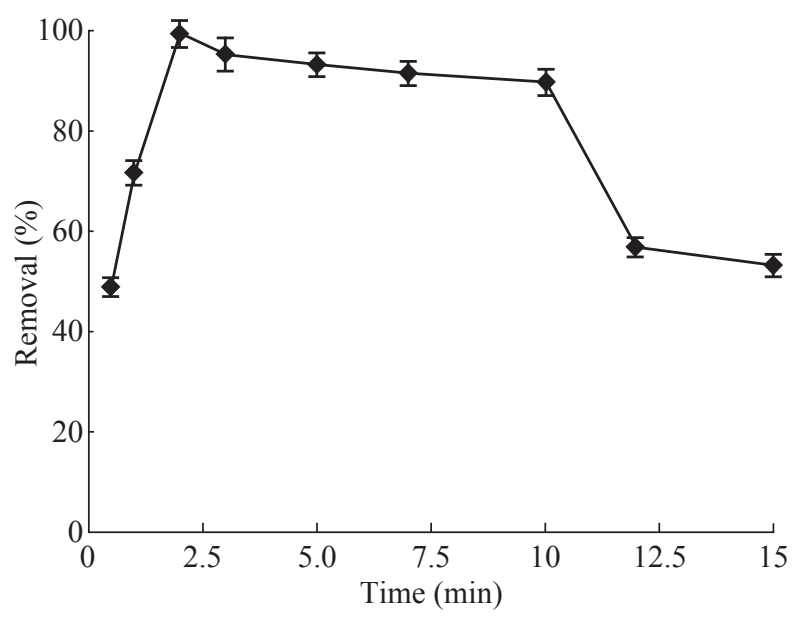

Fig. 8 Effects of desorption duration on drug absorbance level: $\mathrm{PP}$ concentration $1 \mathrm{mg} \cdot \mathrm{ml}^{-1}$, solution volume $50 \mathrm{ml}, \mathrm{pH} 10,5$ $\mathrm{mL}$ of CTAB $(0 / 2 \% \mathrm{w} / \mathrm{v}), 0.07 \mathrm{~g}$ of absorbent, contact time 7 $\mathrm{min}, 1 \mathrm{ml}$ of methanol as desorbent (solvent).

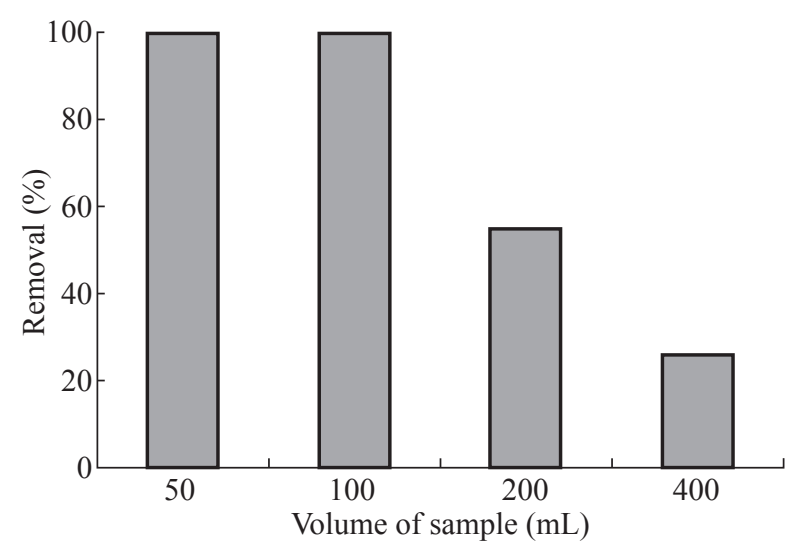

Fig. 9 Effects of volume of sample on drug absorbance level: PP concentration $1 \mathrm{mg} \cdot \mathrm{ml}^{-1}$, $\mathrm{pH} 10,5 \mathrm{~mL}$ of CTAB $(0 / 2 \% \mathrm{w} /$ v), $0.07 \mathrm{~g}$ of absorbent, contact time $7 \mathrm{~min}, 1 \mathrm{ml}$ of methanol as desorbent (solvent).

followed by drug ejection into the reaction mixture. Consequently, optimal pre-concentration level of each sample is proportional to 100 per unite of solvent.

\section{Authenticity and validation of the method}

The proposed method in order to PP solid phase extraction using MNPs was evaluated. To that end, analytical factors such as detection (LOD), limit of quantification (LOQ), relative standard deviation (RSD), and recovery percentage were measured. The calibration curve was established between 0.02-1.2 $\mu \mathrm{g} / \mathrm{ml}$ under optimized experimental conditions with squared regression coefficient of 0.9935 . The equation for this line is: $\mathrm{A}=0.8514 \mathrm{C}_{\mathrm{PP}}+0.0083$ where, $\mathrm{C}_{\mathrm{pp}}$ is the $\mathrm{PP}$ concentration and $\mathrm{A}$ is the absorbance. LOD $(\mathrm{S} /$ 
Table 1 Precision and intra and inter-day variability for the determination of PP $(1 \mu \mathrm{g} / \mathrm{ml})$

\begin{tabular}{ccccc}
\hline \multirow{2}{*}{ Sr. No } & \multicolumn{2}{c}{ Intra-day Precision } & \multicolumn{2}{c}{ Inter-day Precision } \\
\cline { 2 - 3 } \cline { 5 - 6 } & Concentration $(\mu \mathrm{mol} / \mathrm{ml})$ & $\mathrm{RSD}(n=3)(\%)$ & & \multicolumn{2}{c}{ Concentration $(\mu \mathrm{mol} / \mathrm{ml})$} \\
\hline 2 & 0.9754 & 1.13 & 0.9986 & 1.66 \\
3 & 0.960 & 1.76 & 1.0310 & 1.0040 \\
4 & 1.002 & 1.25 & 0.78 & 0.9916 \\
\hline
\end{tabular}

Table 2: Comparison of the proposed method with other reported studies

\begin{tabular}{ccccc}
\hline Method & Linear range $(\mu \mathrm{g} / \mathrm{ml})$ & LOD $(\mu \mathrm{g} / \mathrm{ml})$ & QOD $(\mu \mathrm{g} / \mathrm{ml})$ & RSD* $(\%)$ \\
\hline RAM-HPLC-UV & $0.2-1.5$ & 0.05 & 0.2 & $1.8-8.43$ \\
HPLC-UV & $0.25-4$ & $\mathrm{~N}$ & 0.25 & $4.03-13.73$ \\
SPE-HPLC-UV & $0.1-1.5$ & 0.1 & $\mathrm{~N}$ & $1.11-5.97$ \\
RP-HPLC-UV & $20-120$ & 2.35 & 7.14 & $0.33-0.48$ \\
LLE-HPLC-UV & $0.02-4$ & $\mathrm{~N}$ & 0.02 & $2.67-4.5$ \\
LC-MS-MS & $0.01-3$ & $\mathrm{~N}$ & 0.097 & $1.13-2.86$ \\
Voltammetry & $2.6-350$ & 0.18 & 0.4 & 17 \\
Spectrophotometry & $2.5-40$ & 0.49 & 1.47 & 14 \\
This work & $0.02-1.2$ & 0.01 & 0.04 & $2-2.5$ \\
\hline
\end{tabular}

*RSD of the intra-day and inter-day precision

Table 3: Quantitative recovery of the spiked real samples by CTAB $@ \mathrm{Fe}_{3} \mathrm{O}_{4}$

\begin{tabular}{|c|c|c|c|}
\hline Sample & Spiked PA $(\mu \mathrm{mol} / \mathrm{L})$ & Recovery (\%) & $\operatorname{RSD}(n=3)(\%)$ \\
\hline \multirow{3}{*}{ Human plasma } & 0 & - & - \\
\hline & 0.5 & 84.2 & 4.5 \\
\hline & 1 & 87.7 & 3.87 \\
\hline \multirow{3}{*}{ Water Tape } & 0 & - & - \\
\hline & 0.5 & 91.5 & 1.29 \\
\hline & 1 & 90.3 & 1.67 \\
\hline \multirow{3}{*}{ Water well } & 0 & - & - \\
\hline & 0.5 & 94.3 & 2.05 \\
\hline & 1 & 91.5 & 2.14 \\
\hline
\end{tabular}

$\mathrm{N}=3)$ and $\operatorname{LOQ}(\mathrm{S} / \mathrm{N}=10)$ were found to be 0.014 and $0.04 \mu \mathrm{g} / \mathrm{ml}$, respectively.

To estimate how elaborate and repeatable this method is, the Inter-day and intra-day precision of the developed method were studied (Table 1). In order to calculate intra-day precision, four supernatants of the standard solution were analyzed during a same day and inter-day precision was also performed over four consecutive days, for both under optimal conditions and pre-concentration of the drug. RSD was calculated satisfactory RSD values $1.76 \%$ and $1.48 \%$ were obtained for intra and inter day, respectively, indicating the good repeatability of this method.

The results were compared with that of reported literatures devoted to PP drug determination Table 2. The values of the parameters obtained from reported studies confirm excellent analytical parameters of the current simple assays in compare with traditional methods. Most of these techniques are either suffering from instability of the phases which leads to reach undesired accuracy and precision (see ref. [43] in Table 2) or extravagant expenses of required instruments and sample pretreatment.

\section{Pharmaceutical applications assay}

To assess the competence of this method, it was applied for PP determination in biological, laboratory tap water and subterranean water specimens. Samples 
were spiked to certain extents of PP and triplicated. The recoveries achieved for each samples and standard deviations (RSD) have been given in Table 3. The excellence values of recoveries proved the capability of this methodology to trace PP drug without being impressed by the potential presence of the interferences in such complex matrices.

\section{Conclusion}

In this work, a fast, facile and practical method for determination and pre-concentration of PP drug on the basis of Cetyltrimethylammonium bromide (CTAB) coated with magnetite nano particles was reported. The synthesized carriers were also applied as nano-adsorbents in order to extraction and of this drug in water and biological samples under optimized conditions. Abrupt separation process, minimal amount of requisite organic solvent, and finally reusability feature of such super-magnetic systems has profound impact on economical thrift and time consumption which were the impediments of the traditional separation methods. Moreover, satisfactory amounts of recoveries, linarites, and repeatability along with low limit of detection of this methodology demonstrate that the proposed method is completely feasible in applications of industrial levels. While analytical parameters measured were comparable to the previous works reported.

\section{Acknowledgments}

The authors deeply appreciate the vital contributions of the staff of the Karaj branch of Azad University laboratory, and also the personnel of the SEM laboratory of Tarbiat Modares University, who made this project a success. The results, opinions, and conclusions expressed in this paper are solely those of the authors and do not necessarily reflect those of the sponsoring organizations.

\section{Reference}

[1] P.O. Katz, B.G. Lauren, F.V. Marcelo, Guidelines for the diagnosis and management of gastroesophageal reflux disease. The American Iournal of Gastroenterology, 2013, 108.3: 308-328.

[2] J.M. Shin, S. George, Pharmacology of proton pump inhibitors. Current Gastroenterology Reports, 2008, 10.6: 528-534.

[3] J.M. Mears, B. Kaplan, Proton pump inhibitors: new drugs and indications. American Family Physician, 1996,
53.1: $285-292$.

[4] S. Thanikachalam, R. Manavalan, K. Valliappan, Stabilityindicating HPLC method for simultaneous determination of pantoprazole and domperidone from their combination drug product. Chromatographia, 2008, 67.1-2: 41-47.

[5] N.V.S. Ramakrishna, K.N. Vishwottam, S. Wishu, et al., High-performance liquid chromatography method for the quantification of pantoprazole in human plasma. Journal of Chromatography B, 2005, 822.1: 326-329.

[6] V. Saini, V. B. Gupta, Estimation of pantoprazole from multiparticulate dosage form by new HPLC method. International Journal of Pharmaceutical Research, 2009, 1.4: 1094-1096.

[7] H.Y. Xu, L. Yang, P. Zhang, et al., Determination of pantoprazole in human plasma by HPLC. Journal of Shenyang Pharmaceutical University, 2008, 1: 009.

[8] T. Sivakumar, R. Manavalan, C. Muralidharan, et al., Multi-criteria decision making approach and experimental design as chemometric tools to optimize HPLC separation of domperidone and pantoprazole. Journal of Pharmaceutical and Biomedical Analysis, 2007, 43.5: 1842-1848.

[9] M. Tanaka, Y. Hideki, Direct determination of pantoprazole enantiomers in human serum by reversedphase high-performance liquid chromatography using a cellulose-based chiral stationary phase and columnswitching system as a sample cleanup procedure. Analytical Chemistry, 1996, 68.9: 1513-1516.

[10] B. Prasanna Kumar Reddy, Y. Ramanjaneya Reddy, D. Ramachandran, Determination of pantoprazole sodium and lansoprazole in individual tablet dosage forms by RPHPLC using single mobile phase. Journal of Chemistry, 2009, 6.2: 489-494.

[11] S. Gosavi, A. Shirkhedkar, Y. Jaiswal, et al., A simple and sensitive HPTLC method for quantitative analysis of pantoprazole sodium sesquihydrate in tablets. JPCJournal of Planar Chromatography-Modern TLC, 2006, 19.109: 228-232.

[12] G.H. Patel, S.T. Prajapati, C.N. Patel, HPTLC Method development and validation for simultaneous determination of cinitapride and Pantoprazole in capsule dosage form. Research Journal of Pharmacy and Technology, 2011, 4.9: 1428-1431.

[13] A. Radi, Square-wave adsorptive cathodic stripping voltammetry of pantoprazole. Journal of Pharmaceutical and Biomedical Analysis, 2003, 33.4: 687-692.

[14] N. Erk, Differential pulse anodic voltammetric determination of pantoprazole in pharmaceutical dosage forms and human plasma using glassy carbon electrode. Analytical Biochemistry, 2003, 323.1: 48-53.

[15] A. Radi, Determination of pantoprazole by adsorptive stripping voltammetry at carbon paste electrode I1. Farmaco, 2003, 58.7: 535-539.

[16] O. Peres, C.H. Oliveira, R.E. Barrientos-Astigarraga, et al., Determination of pantoprazole in human plasma by LC-MS-MS using lansoprazole as internal standard. Arzneimittel-forschung, 2003, 54.6: 314-319.

[17] B.R. Challa, H.B. Sai, Z.A. Bahlul, et al., Development and validation of a Sensitive bioanalytical method for the quantitative estimation of Pantoprazole in human plasma samples by LC-MS/MS: Application to bioequivalence study. Journal of Chromatography B, 2010, 878.19: 14991505.

[18] A.A.M. Wahbi, O. Abdel-Razak, A.A. Gazy, et al., Spectrophotometric determination of omeprazole, lansoprazole and pantoprazole in pharmaceutical formulations. Journal of Pharmaceutical and Biomedical Analysis, 2002, 30.4: 1133-1142.

[19] K. Basavaiah, U.R. Anil Kumar, Sensitive spectrophotometric methods for the determination of 
pantoprazole sodium in pharmaceuticals using bromatebromide, methyl orange and indigo carmine as reagents. Indian Journal of Chemical Technology, 2007, 14.6: 611.

[20] R. Angel, M. Zougagh, M. Bouri, Magnetic (nano) materials as an useful tool for sample preparation in analytical methods, A review. Analytical Methods, 2013, 5.18: 4558-4573.

[21] D. Louch, S. Motlagh, J. Pawliszyn, Dynamics of organic compound extraction from water using liquid-coated fused silica fibers. Analytical Chemistry, 1992, 64.10: 1187-1199.

[22] H. Prosen, Z.K. Lucija, Solid-phase microextraction. TrAC Trends in Analytical Chemistry, 1999, 18.4: 272282

[23] S. Zhang, H. Niu, Z. Hu, et al., Preparation of carbon coated $\mathrm{Fe}_{3} \mathrm{O}_{4}$ nanoparticles and their application for solidphase extraction of polycyclic aromatic hydrocarbons from environmental water samples. Journal of Chromatography A, 2010, 1217.29: 4757-4764.

[24] H.J. Kim, J.E. Ahn, S. Haam, et al., Synthesis and characterization of mesoporous $\mathrm{Fe} / \mathrm{SiO}_{2}$ for magnetic drug targeting. Journal of Materials Chemistry, 2006, 16.17: 1617-1621.

[25] S. Tapas, A. Sebastianelli, I.J. Bruce, Mesoporous silicamagnetite nanocomposite: fabrication and applications in magnetic bioseparations. Journal of the American Chemical Society, 2006, 128.22: 7130-7131.

[26] J. He, M. Huang, D. Wang, et al., Magnetic separation techniques in sample preparation for biological analysis: A review. Journal of Pharmaceutical and Biomedical Analysis, 2014, 101: 84-101.

[27] Y. Liu, H. Li, J. Lin, Magnetic solid-phase extraction based on octadecyl functionalization of monodisperse magnetic ferrite microspheres for the determination of polycyclic aromatic hydrocarbons in aqueous samples coupled with gas chromatography-mass spectrometry. Talanta, 2009, 77.3: 1037-1042.

[28] H. Chaozhang, B. Hu, Silica-coated magnetic nanoparticles modified with $\gamma$-mercaptopropyltrimetho xysilane for fast and selective solid phase extraction of trace amounts of $\mathrm{Cd}, \mathrm{Cu}, \mathrm{Hg}$, and $\mathrm{Pb}$ in environmental and biological samples prior to their determination by inductively coupled plasma mass spectrometry. Spectrochimica Acta Part B: Atomic Spectroscopy, 2008, 63.3: 437-444.

[29] J. Li, X. Zhao, Y. Shi, et al., Mixed hemimicelles solidphase extraction based on cetyltrimethylammonium bromide-coated nano-magnets $\mathrm{Fe}_{3} \mathrm{O}_{4}$ for the determination of chlorophenols in environmental water samples coupled with liquid chromatography/spectrophotometry detection. Journal of Chromatography A, 2008, 1180.1: 24-31.

[30] B. Zargar, H. Parham, A. Hatamie, Fast removal and recovery of amaranth by modified iron oxide magnetic nanoparticles. Chemosphere, 2009, 76.4: 554-557.

[31] H. Parham, B. Zargar, Z. Heidari, et al., Magnetic solid-phase extraction of Rose Bengal using iron oxide nanoparticles modified with cetyltrimethylammonium bromide. Journal of the Iranian Chemical Society, 2011, 8.1: S9-S16.

[32] A.A. Rajabi, Y. Yamini, M. Faraji, et al., Solid-phase microextraction based on cetyltrimethylammonium bromide-coated magnetic nanoparticles for determination of antidepressants from biological fluids. Medicinal Chemistry Research, 2013, 22.4: 1570-1577.

[33] M. Faraji, Y. Yamini, M. Rezaee, Extraction of trace amounts of mercury with sodium dodecyle sulphatecoated magnetite nanoparticles and its determination by flow injection inductively coupled plasma-optical emission spectrometry. Talanta, 2010, 81.3: 831-836.

[34] A. Beiraghi, K. Pourghazi, M. Amoli-Diva, et al., Magnetic solid phase extraction of mefenamic acid from biological samples based on the formation of mixed hemimicelle aggregates on $\mathrm{Fe}_{3} \mathrm{O}_{4}$ nanoparticles prior to its HPLC-UV detection. Journal of Chromatography $B$, 2014, 945: 46-52.

[35] Z. Hong-Fei, Y.P. Shi, Pretreatment properties of CTAB coated $\mathrm{Fe}_{3} \mathrm{O}_{4}$ nanoparticle mixed hemimicelle sorbents for the analysis of herbal medicine samples. Current Analytical Chemistry, 2012, 8.1: 150-158.

[36] M. Bolhassani, M. Sayyahmanesh, A study on mechanical properties of cement paste using magnetite-silica nanocomposites. Advances in Cement Research (ACR), 2015.

[37] L. Sun, C. Zhang, L. Chen, et al., Preparation of alumina-coated magnetite nanoparticle for extraction of trimethoprim from environmental water samples based on mixed hemimicelles solid-phase extraction. Analytica Chimica Acta, 2009, 638.2: 162-168.

[38] S. Zhang, H. Niu, Z. Hu, et al., Preparation of carbon coated $\mathrm{Fe} 3 \mathrm{O} 4$ nanoparticles and their application for solid-phase extraction of polycyclic aromatic hydrocarbons from environmental water samples. Journal of Chromatography A, 2010, 1217.29: 4757-4764.

[39] Q.B. Cassa, A.L.G. Degani, N.M. Cassiano, et al., Enantiomeric determination of pantoprazole in human plasma by multidimensional high-performance liquid chromatography. Journal of Chromatography B, 2002, 766.1: 153-160.

[40] B. Koçyiğit-Kaymakçoğlu, S. Ünsalan, S. Rollas, Determination and validation of ketoprofen, pantoprazole and valsartan together in human plasma by high performance liquid chromatography. Die Pharmazie-An International Journal of Pharmaceutical Sciences, 2006, 61.7: 586-589.

[41] M.L. Storms, J.T. Stewart, Development of a reversedphase liquid chromatographic method for the analysis of amoxicillin, metronidazole, and pantoprazole in human plasma using solid-phase extraction. Journal of Liquid Chromatography \& Related Technologies, 2002, 25.16: 2433-2443.

[42] B. Siddartha, I.S. Babu, Ch. Ravichandra Gupta, U.P. Panigrahy, Analytical method development and validation for simultaneous estimation of Mosapride and Pantoprazole in bulk \& pharmaceutical dosage form by RP-HPLC method. Journal of Advanced Pharmacy Education \& Research, 2014, 4.2.

[43] M. Noubarani, F. Keyhanfar, M. Motevalian, et al., Improved HPLC method for determination of four PPIs, omeprazole, pantoprazole, lansoprazole and rabeprazole in human plasma. Journal of Pharmacy \& Pharmaceutical Sciences, 2010, 13.1: 1-10.

[44] Z.O. Devi, K. Basavaiah, K.B. Vinay, Sensitive and selective spectrophotometric determination of pantoprazole sodium in pharmaceuticals using permanganate. Chemical Industry and Chemical Engineering Quarterly, 2010, 16.1: 97-102.

Copyright $(\underset{C}{ } 2015$ Maryam Sayyahmanesh, Ebrahim Naghian, Hamed Sahebi and Sara Asgari. This is an open-access article distributed under the terms of the Creative Commons Attribution License, which permits unrestricted use, distribution, and reproduction in any medium, provided the original author and source are credited. 